\title{
Iron metabolism and erythropoiesis after surgery
}

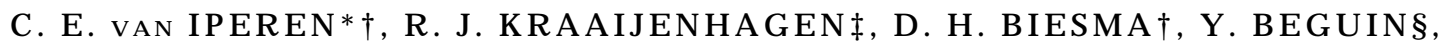 \\ J.J.M.MARX† and A. VAN DE WIEL*
}

Departments of *Internal M edicine and $\ddagger C$ linical Chemistry, E emland H ospital, Amersfoort and †D epartment of Internal M edicine and E ijkman-Winkler Institute, University H ospital U trecht, U trecht, The N etherlands, and §D epartment of M edicine, Division of Haematology, University of Liege, L iege, Belgium

Correspondence to: Dr C. E. van I peren, Department of Internal M edicine, University H ospital U trecht, H eidelberglaan 100, 3584 CX Utrecht, The N etherlands

Background This was a prospective study comparing the effect of major and minor surgery on haematological variables concerning erythropoiesis, iron metabolism and acute-phase response proteins.

Methods Thirty-one otherwise healthy patients, 15 having major orthopaedic surgery and 16 undergoing minor surgery, were studied. Blood samples were taken before surgery and 1, 4, 10 and 28 days after operation.

Results $\mathrm{H}$ aemoglobin concentration was decreased for up to 4 weeks after surgery. Serum erythropoietin concentration and reticulocyte count were raised after major surgery only. Serum iron concentration dropped the day after major (to 23 per cent of its preoperative level) and minor (to 46 per cent of its preoperative level) surgery and remained lower for up to 28 days after major surgery. Serum transferrin concentration and transferrin saturation decreased after both types of surgery while ferritin concentration increased. Serum transferrin receptor concentration increased only 4 weeks after major surgery $(P<0.01)$. The interleukin 6 peak (day 1$)$ was greater after major than minor surgery, as was the C-reactive protein peak (day 4).

Conclusion Both major and minor surgery induce a state of hypoferraemia in the presence of adequate iron stores. The degree of this transient form of 'anaemia of chronic disease' is related to the extent of surgery. I ron supplementation in the first weeks after surgery (if iron stores were normal before operation) is ineffective.

A naemia after surgery could be explained by blood loss during and after operation. However, there is evidence that the characteristics of postoperative anaemia are more similar to those of the anaemia of chronic disease (ACD) rather than iron deficiency ${ }^{1,2}$. ACD is seen in patients with inflammatory disorders and malignancy ${ }^{3-5}$. This type of anaemia is characterized by a decrease in plasma iron and transferrin levels despite adequate iron stores, and a reduction in erythropoiesis $s^{3-5}$. The mechanism of postoperative anaemia remains unknown although it could be an acute-phase 'inflammatory' effect of surgery ${ }^{6-10}$. The contribution of tissue damage, anaesthesia and blood loss to the extent of anaemia was studied in patients undergoing major and minor surgery.

\section{Patients and methods}

Thirty-one patients were included; 15 had major elective orthopaedic surgery and 16 had a minor surgical procedure (minimal blood loss, short operation). M ajor surgery included total hip replacement (12 patients), total knee replacement (one) and laminectomy (two). M inor surgery was correction of hallux valgus/exostosis (seven), arthroscopy of the knee (two), shoulder arthroplasty (four), laparoscopic repair of inguinal hernia (two) and laparoscopic cholecystectomy (one). No patient had a history of chronic inflammatory disease and all had normal preoperative levels of haemoglobin, serum ferritin, folic acid and vitamin $B_{12}$. Participants in an autologous blood transfusion programme were excluded. No patient had evidence of postoperative infection or haemolysis. No oral iron supplements were allowed during the study. This study was approved by the Medical Ethical

Paper accepted 15 J une 1997
Committee of E emland H ospital. Informed consent was given by all patients.

$\checkmark$ enous blood was taken at 08.00 hours on the day before the scheduled operation and on days 1, 4, 10 and 28 after operation. Total blood count was measured (E-5000 Hematology A nalyser; Sysmex Toa, Kobe, Japan) including reticulocyte count (flow cytometric analysis; Sysmex R -1000) ${ }^{11}$. Serum erythropoietin was measured by an enzyme-linked immunosorbent assay (ELISA) (Boehringer, M annheim, Germany; normal range 0.4-9.0 units/ I). Serum transferrin receptor was determined as described previously (normal range $3.8-7.2 \mathrm{mg} / /)^{12,13}$. I ron metabolism was further analysed by measuring serum iron ( $\mathrm{H}$ itachi 717 ; normal value $10-30 \mu \mathrm{mol} / \mathrm{l}$ ), serum transferrin (normal value $2 \cdot 2-3.6 \mathrm{~g} /$ I), transferrin saturation (calculated from serum iron and transferrin concentration; normal value $0.20-0.45$ ) and serum ferritin (normal value 20-200 $\mu \mathrm{g} / \mathrm{l}$ ). C-reactive protein (CRP) was measured by turbidimetry ( $\mathrm{H}$ itachi 717, Boehringer, M annheim, Germany; normal value $0-10 \mathrm{mg} / \mathrm{l}$ ). Interleukin (IL) 6 (normal value less than $8 \mathrm{ng} / \mathrm{l}$ ) and tumour necrosis factor (TNF) $\alpha$ (normal value less than $40 \mathrm{ng} / \mathrm{l})$ were measured in serum using an ELISA ${ }^{14,15}$.

$D$ ata are given as mean(s.d.). Statistical significance was assessed using Student's $t$ test (two-sided). Non-parametric variables were tested with a $\chi^{2}$ test. Correlations were analysed with the $M$ ann-Whitney $U$ test and Spearman rank correlation coefficient. Significance was accorded with a P value of less than 0.05 .

\section{Results}

Demographic and perioperative characteristics are listed in Table 1. Blood transfusion was necessary in two patients with excessive blood loss (more than $1200 \mathrm{ml}$ ) after total hip replacement.

Mean preoperative values of all haematological variables tested did not differ significantly between the 
Table 1 D emographic and perioperative characteristics of the 31 patients undergoing surgery

\begin{tabular}{llc}
\hline & M ajor surgery & M inor surgery \\
\hline Sex ratio ( $: M)$ & $11: 4$ & $6: 10$ \\
R egional anaesthesia & 13 & 7 \\
G eneral anaesthesia & 2 & 9 \\
A ge (years) & $65(11)$ & $4(10) *$ \\
$\begin{array}{l}\text { Blood loss during } \\
\text { operation (ml) }\end{array}$ & $553(279)$ & $7(20)^{*}$ \\
$\begin{array}{l}\text { Blood loss after } \\
\text { surgery (ml) }\end{array}$ & $530(288)$ & $56(23)^{*}$ \\
$\begin{array}{l}\text { Duration of operation } \\
\text { (min) }\end{array}$ & $127(33)$ & \\
Intravenous fluids (ml) & & $1300(800)^{*}$ \\
$\quad$ During operation & $3400(400)$ & $300(800) \dagger$ \\
$\quad$ A fter operation & $1000(700)$ & \\
\hline
\end{tabular}

$\checkmark$ alues are mean(s.d.). $* P<0.001,+P<0.05$ versus major surgery (Student's t test)

groups. Changes in haemoglobin and serum erythropoietin concentration are shown in Fig. 1. There was a small, non-significant increase in reticulocyte count 1 week after major surgery (preoperative value 68(19) $\times 10^{9} / \mathrm{l}$ maximum value $\left.95(23) \times 10^{9} / 1\right)$. The changes in iron metabolism are shown in Fig. 2. The decrease in serum iron and transferrin concentration as well as in transferrin saturation the day after surgery was greater after major than minor surgery $(P<0.01)$. The acute-phase reaction after surgery is documented by an increase in serum ferritin and CRP (Fig. 3) and IL-6 concentration ${ }^{6,8,9}$. The CRP peak after surgery was significantly higher after major surgery $(P<0.01)$. IL -6 concentration increased the day after surgery from $40(18)$ to $138(151) \mathrm{pg} / \mathrm{ml}$ after major surgery $(P<0.01)$ and from $30(14)$ to $62(45) \mathrm{pg} / \mathrm{ml}$ after minor surgery $(P<0.01)$ with a rapid fall thereafter. No significant increase in TNF- $\alpha$ concentration could be detected after surgery (data not shown). The relation between clinical data, markers of the acute-phase reaction and the haematological variables was tested. The duration of operation correlated significantly with the peak CRP level $\left(r_{\mathrm{s}}=0.65, P<0.001\right)$ and the blood loss correlated with the decrease in haemoglobin concentration the day after surgery $\left(r_{s}=0.72, P<0.001\right)$. The lowest haemoglobin value after surgery correlated significantly with the peak serum erythropoietin concentration $\left(r_{s}=0.49\right.$ $P<0.05)$. Peak CRP concentration was proportional to the maximum decrease in serum iron $\left(r_{s}=0.37, P=0.05\right)$ and transferrin $\left(r_{s}=0.54, P<0.01\right)$ concentration as well as with the decrease in haemoglobin concentration on the day after surgery $\left(r_{s}=0.69, \mathrm{P}<0.001\right)$ and the peak serum erythropoietin concentration $\left(r_{s}=0.66, P<0.001\right)$. No significant correlation could be found between the peak IL-6 concentration and the other haematological variables. In a subanalysis of the minor surgery group according to the method of anaesthesia (nine general, seven regional) no differences could be found with respect to changes in iron metabolism and erythropoiesis (results not shown).

\section{Discussion}

Postoperative anaemia has not been studied extensively because it was thought simply to be due to blood loss at operation. Such anaemia was easily treated with red blood cell transfusion and/or supplementation with iron. The disadvantages of blood transfusion such as transmission of viral infections and impairment of the immune system have drawn attention to alternative options ${ }^{16}$. It has been shown that iron supplementation after hip surgery has no major effect on erythropoiesis ${ }^{1,2}$. A nalysis of the mechanism of postoperative anaemia may give more insight into changes in iron metabolism and may have clinical relevance.

In this study, surgery led to distinctive changes in iron metabolism: a decrease in the serum levels of iron and
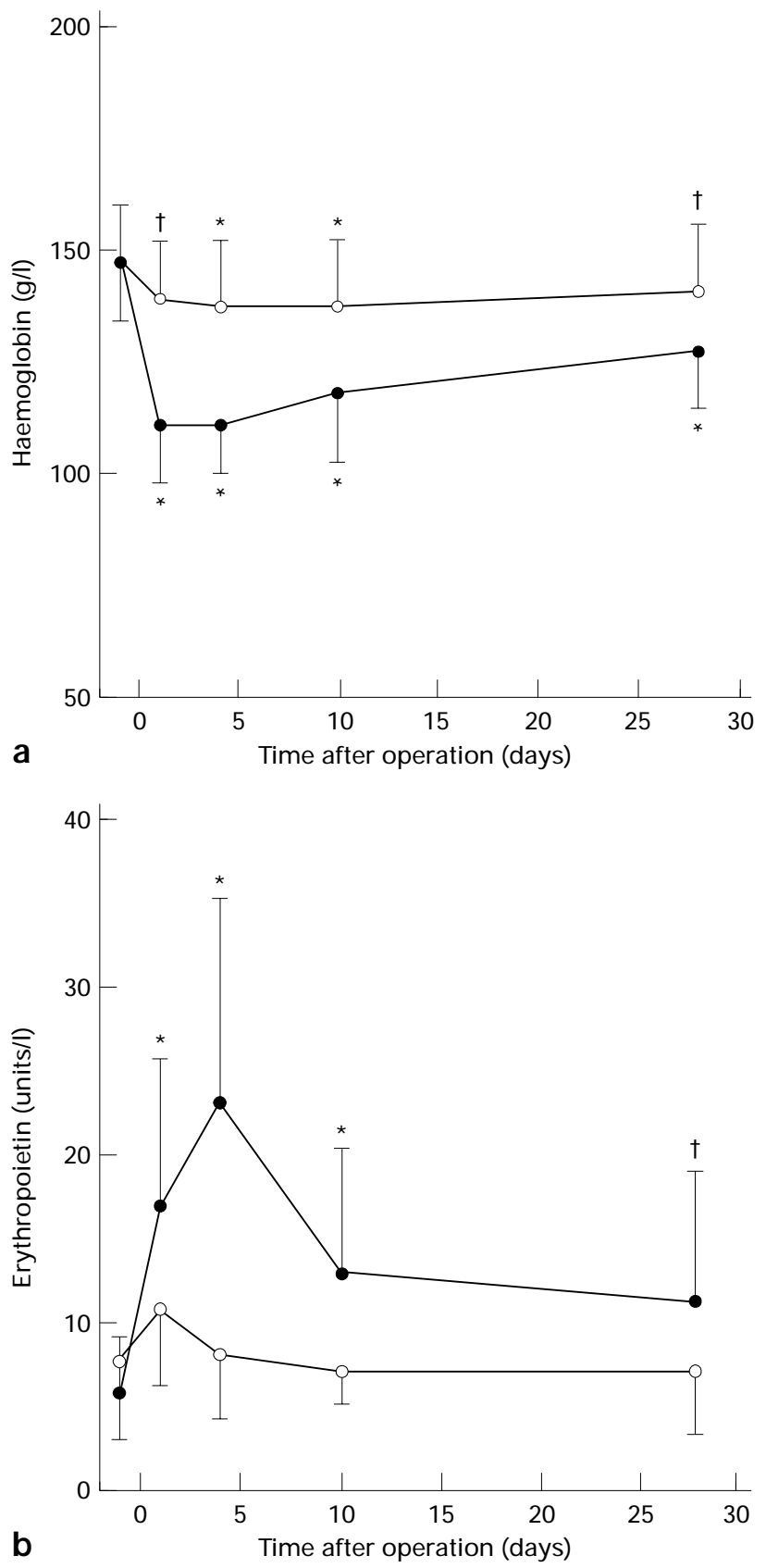

Fig. 1 a M ean(s.d.) haemoglobin concentration and b serum erythropoietin concentration in 31 patients undergoing major $(\bullet)$ or minor $(O)$ surgery. $* P<0.001,+P<0.01$ versus preoperative value (Student's t test) 
transferrin and in transferrin saturation, and an increase in serum ferritin concentration ${ }^{1,17-19}$. These changes mimic those found in ACD and indicate a functional iron deficiency. This is in contrast to uncomplicated iron deficiency where low serum iron levels and transferrin saturation are accompanied by an increase in serum transferrin and a decrease in ferritin concentration. In the present patients serum transferrin receptor concentrations were normal (less than $6.0 \mathrm{mg} / \mathrm{l}$ ) after surgery. A n increase in these receptor values is seen in increased erythropoiesis as well as in iron deficiency (greater than
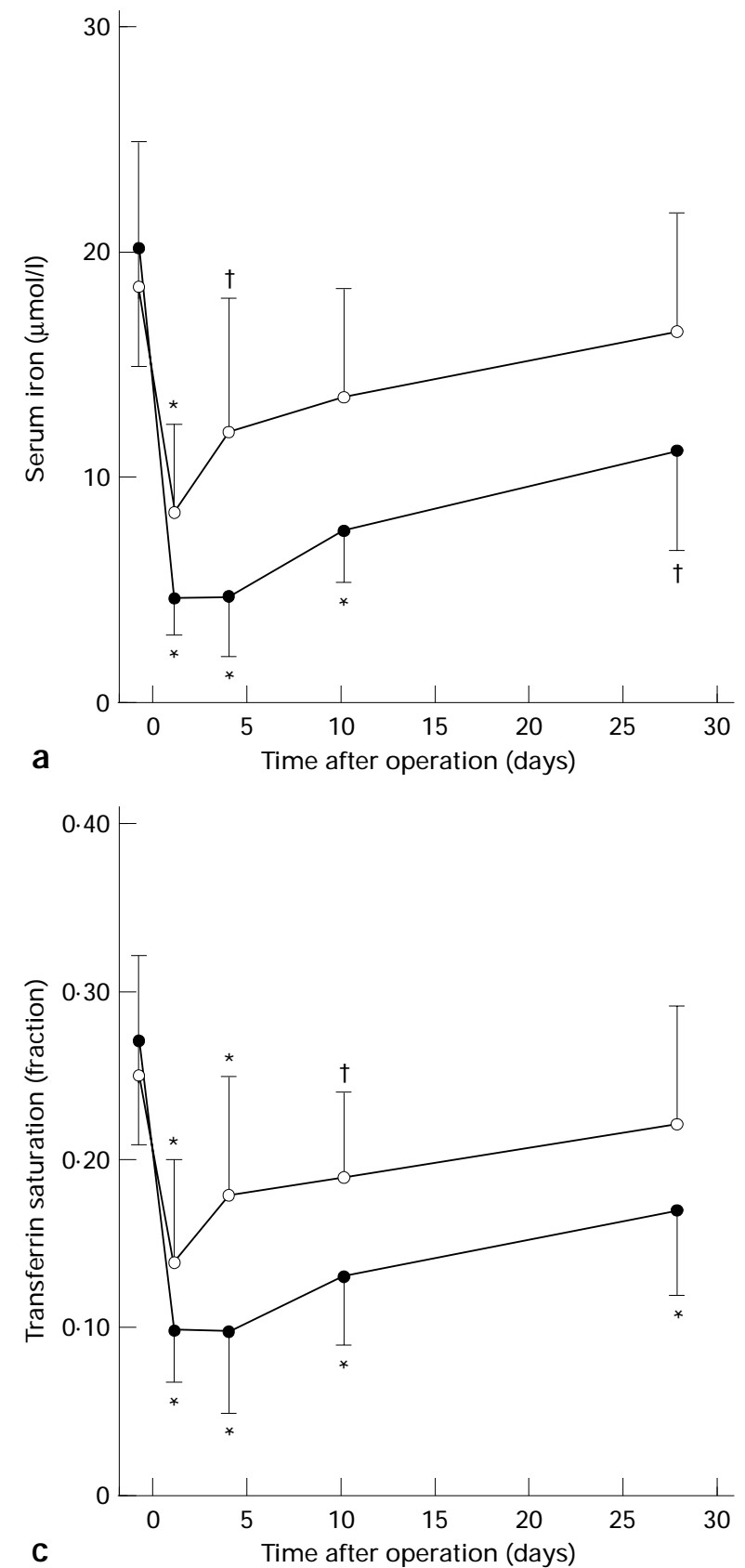

$8.5 \mathrm{mg} / \mathrm{l})^{12,20}$. In ACD, serum transferrin receptor concentrations are believed to be normal ${ }^{20}$. The hypothesis from this study is that after surgery signs of iron deficiency are overruled by those of anaemia of inflammation. In the first weeks after surgery, there is a failure of the bone marrow to increase erythropoiesis in response to the anaemia, as indicated by the minimal change in transferrin receptor levels or reticulocyte count. Only 4 weeks after major surgery was an increase in soluble transferrin receptor concentration observed, indicating increased erythropoiesis, while iron became
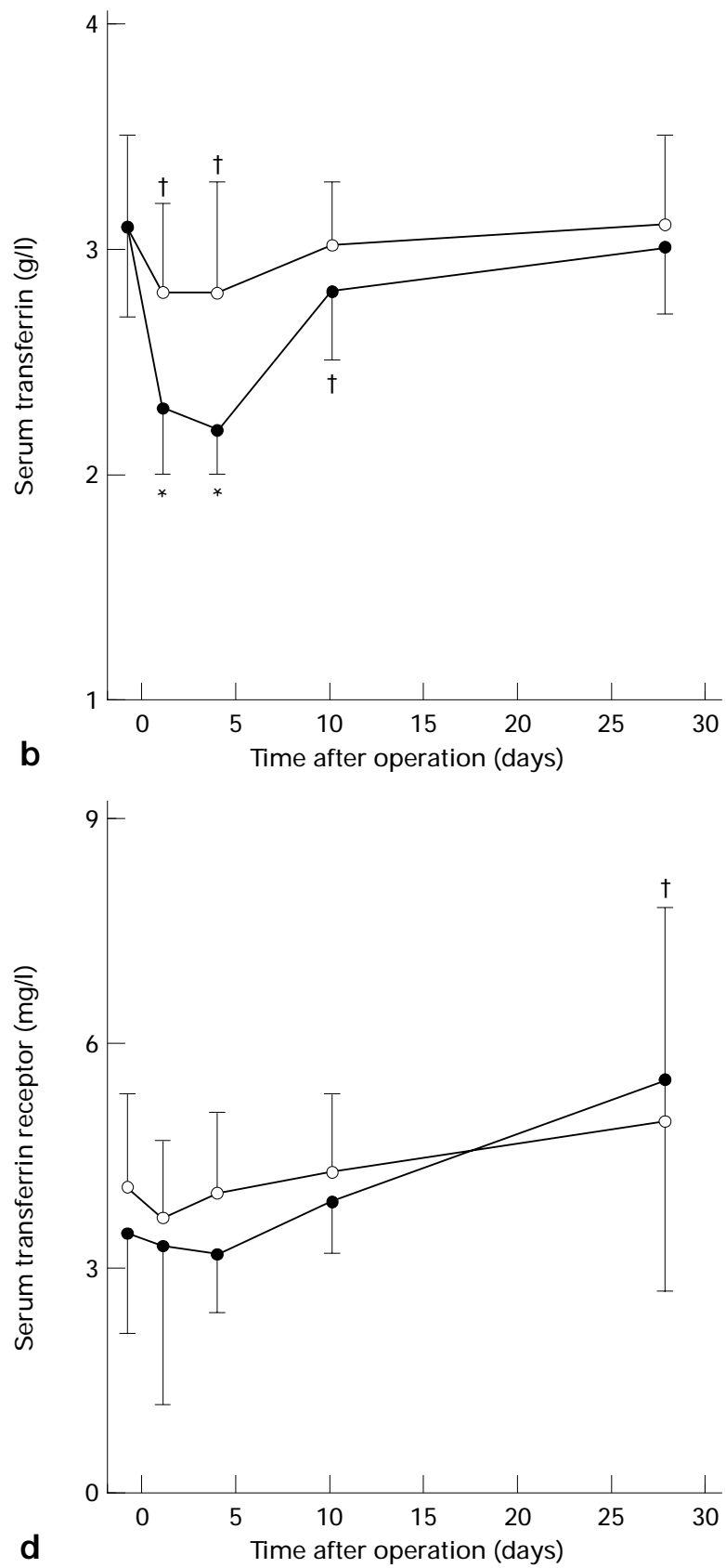

Fig. 2 Changes in iron metabolism in 31 patients undergoing major $(\bullet)$ or minor $(\bigcirc)$ surgery. Values are mean(s.d.); a serum iron concentration, $\mathbf{b}$ serum transferrin concentration, $\mathbf{c}$ transferrin saturation and $\mathbf{d}$ serum transferrin receptor concentration. $* \mathrm{P}<0.001$ $+\mathrm{P}<0.01$ versus preoperative value (Student's t test) 
more available, reflected by increased serum iron levels and transferrin saturation. These findings explain the ineffectiveness of iron supplementation during the first weeks after surgery if normal iron stores are present before operation.

This study also shows that even minor surgery has a significant impact on iron metabolism, although changes are milder and recovery is faster than after major surgery. This indicates that blood loss is not essential in inducing changes in iron status. The method of anaesthesia seems
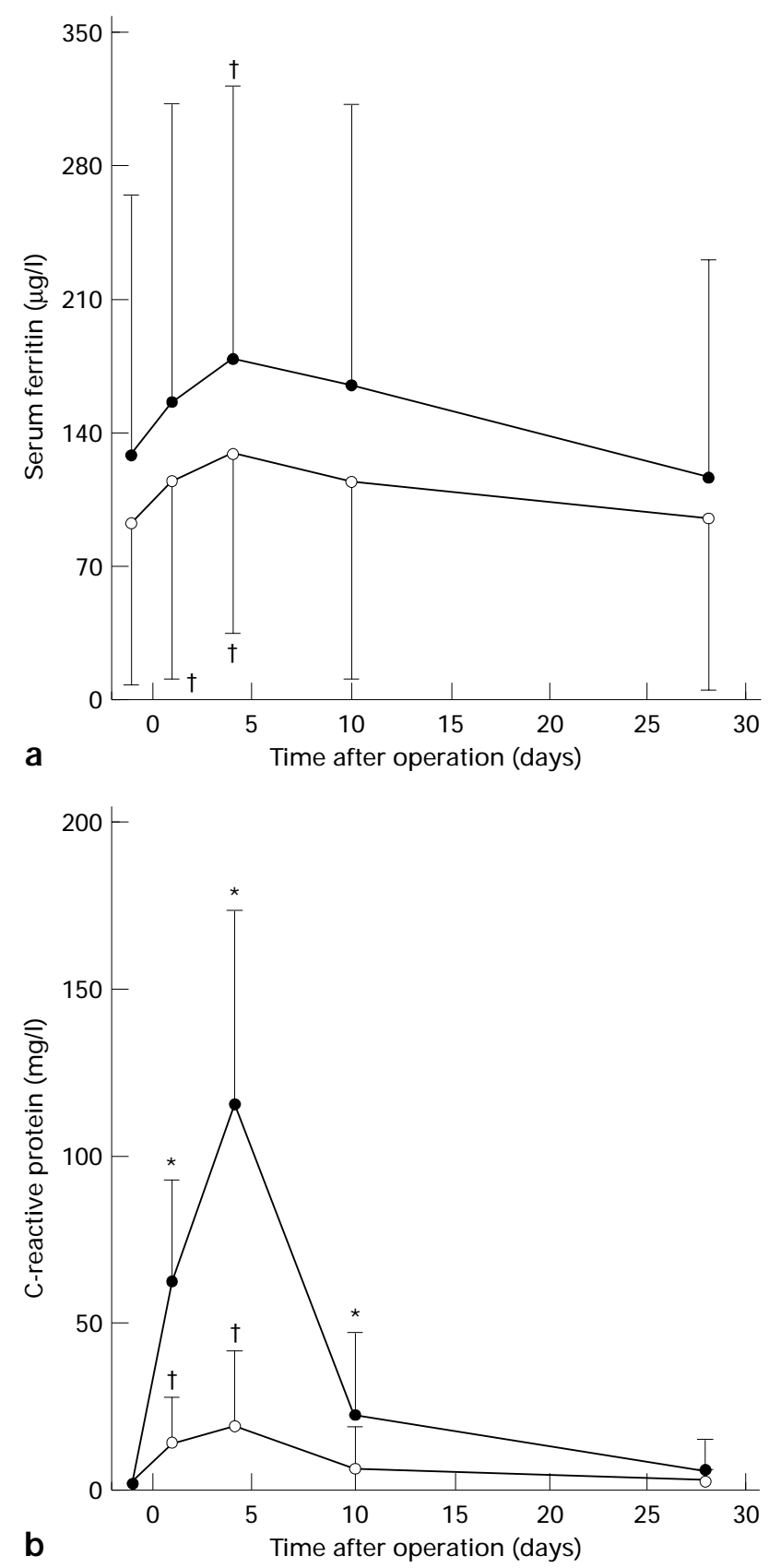

Fig. 3 a $M$ ean(s.d.) serum ferritin and $\mathbf{b}$ C-reactive protein concentration in 31 patients undergoing major $(\mathbf{O})$ or minor $(O)$ surgery. $* P<0.001,+P<0.01$ versus preoperative value (Student's t test) to have no influence, in accordance with a study on serum iron after hysterectomy using two different types of anaesthesia ${ }^{21}$. The extent of surgery does influence iron metabolism. A more major operation results in a greater and more prolonged change in iron parameters, suggesting that the changes in iron metabolism are related to tissue damage. A marked acute-phase response was found after both types of surgery, although it was greater after major surgery. The concentration of IL-6, one of the most important acute-phase mediators, was increased the day after surgery. The CR P level was greatest 4 days after operation. The production of CRP by hepatocytes is induced by $\mathrm{IL}-6^{22}$. No increase in $T N F-\alpha$, another mediator of the acute-phase response, was found after surgery in this study. A direct relation between cytokines and altered iron metabolism is described in chronic inflammation ${ }^{5,23,24}$. The release of cytokines leads to iron uptake by activated macrophages ${ }^{24}$. Cytokines (IL - I, IL-6) are directly involved in increased ferritin synthesis, which is under translational control $\left.\right|^{25,26 .}$ In this study, the rise in CRP and fall in serum iron and transferrin concentration correlated significantly. M inor tissue damage can initiate an acute-phase reaction including the release of cytokines, and is sufficient to produce changes in iron metabolism.

E ven 1 month after both types of surgery, the haemoglobin concentration had not returned to the preoperative level. This cannot be ascribed to perioperative blood loss, dilution or blood sampling for this study. The changes in iron metabolism and the relative unavailability of iron for erythropoiesis after surgery may contribute to this prolonged postoperative anaemia. The inflammatory cytokines may also have a direct influence on postoperative erythropoiesis 5 . IL-6 may, unlike IL-1, stimulate rather than depress erythropoiesis ${ }^{27}$, but IL-6 also induces anaemia by increasing plasma volume ${ }^{28,29}$. Further studies are necessary to gain more insight into a possible stress factor. An effect of cortisol has been suggested but is unlikely since cortisol concentration can be decreased after surgery too, similar to serum iron ${ }^{21}$.

In conclusion, both major and minor surgery induce a state of hypoferraemia in the presence of adequate iron stores, and a marked acute-phase response. The degree of this transient anaemia is related to the extent of the surgical insult. Iron supplementation in the presence of normal iron stores is ineffective at this time.

\section{Acknowledgements}

The authors thank P. A. L. Blokzeyl, K. M. J. F. L. Lindner and M. P. J. van der List, orthopaedic surgeons, and W. L. M. Kramer, surgeon, Eemland Hospital, A mersfoort for their collaboration; $\mathrm{Dr}$ B. Bast, Department of Immunology, U niversity $H$ ospital U trecht, for measuring TNF- $\alpha$ and IL-6; and $\mathrm{DrH}$. B. M. van de Wiel for performing the statistical analysis.

\section{References}

1 Biesma $D H, V$ an de Wiel $A$, Beguin $Y, K$ raayenhagen $R$, $M \operatorname{arx} J J M$. Post-operative erythropoesis is limited by the inflammatory effect of surgery on iron metabolism. Eur J Clin Invest 1995; 25: 383-9.

2 Zauber NP, Zauber AG, Gordon FJ, Tillis AC, Leeds HC, Berman $E$ et al. Iron supplementation after femoral head replacement for patients with normal iron stores. JAMA 1992; 267: 525-7.

3 Cartwright GE. The anemia of chronic disorders. Semin Hematol 1966; 3: 351-75. 
4 Lee GR. The anemia of chronic disease. Semin Hematol 1983; 20: 61-80.

5 M eans RT Jr, Krantz SB. Progress in understanding the pathogenesis of the anaemia of chronic disease. Blood 1992; 80: $1639-47$.

6 MCM ahon AJ, O'D wyer PJ, Cruikshank AM, M CM illan DC, 0 'R eilly DSt], Lowe GDO et al. Comparison of metabolic responses to laparoscopic and minilaparotomy cholecystectomy. Br J Surg 1993; 80: 1255-8.

$7 \mathrm{Stahl}$ W M. A cute phase protein response to tissue injury. Crit Care Med 1987; 15: 545-50.

8 Chernow B, A lexander HR, Smallbridge RC, Thompson WR, Cook D, Beardsley $D$ et al. Hormonal responses to graded surgical stress. Arch Intern Med 1987; 147: 1273-8.

9 Baigrie RJ, Lamont PM, K wiatkowski D, Dallman MJ, $\mathrm{M}$ orris PJ. Systemic cytokine response after major surgery. $\mathrm{Br}$ J Surg 1992; 79: 757-60.

10 Cruickshank AM, Fraser WD, Burns HJG, Van Damme J, Shenkin A. Response of serum interleukin- 6 in patients undergoing elective surgery of varying severity. Clin Sci 1990; 79: 161-5.

11 Bowen D, Bentley N, Hoy T, Cavill I. Comparison of a modified thiazole orange technique with a fully automated analyser for reticulocyte counting. J Clin Pathol 1991; 44: 130-3.

12 H uebers $H A$, Beguin $Y$, Pootrakul $P, E$ inspahr $D$, Finch CA Intact transferrin receptors in human plasma and their relation to erythropoiesis. Blood 1990; 75: 102-7.

13 Beguin Y, Clemons GK, Pootrakul P, Fillet G. Q uantitative assessment of erythropoiesis and functional classification of anemia based on measurements of serum transferrin receptor and erythropoietin. Blood 1993; 81: 1067-76.

14 Helle $M$, Boeije $L$, de Groot $E$, de Vos A, Aarden L. Sensitive ELISA for interleukin-6. Detection of IL-6 in biological fluids: synovial fluids and sera. I Immunol Methods 1991; 138: 47-56.

15 Tracey KJ, Cerami A. Tumor necrosis factor: an updated review of its biology. Crit Care Med 1993; 21(10 Suppl): S415-22.

16 Consensus conference. Perioperative red blood cell transfusion. JAMA 1988; 260: 2700-3.
17 Paterson IM. A study on the mechanism of the postoperative fall in serum iron concentration. J Surg Res 1986; 41: 587-92.

18 Fraser WD, Taggart DP, Fell GS, Lyon TDB, Wheatley D, Garden $O f$ et al. Changes in iron, zinc, and copper concentrations in serum and in their binding to transport proteins after cholecystectomy and cardiac surgery. Clin Chem 1989; 35: 2243-7.

19 Fitzsimons EJ, Ballantyne GH. Changes in serum iron and leukocyte count associated with open-heart surgery. Clin Chem 1983; 29: 1984-6.

20 Ferguson BJ, Skikne BS, Simpson KM, Baynes RD, Cook JD. Serum transferrin receptor distinguishes the anemia of chronic disease from iron deficiency anemia. J Lab Clin Med 1992; 119: 385-90.

21 Böhrer $\mathrm{H}$, Quintel M, Fischer M V. Clinical evaluation of electrostimulation anaesthesia for hysterectomy. Acta Anaesthesiol Scand 1991; 35: 529-34.

22 Castell JV, A ndus T, Kunz D, Heinrich PC. Interleukin-6. The major regulator of acute-phase protein synthesis in man and rat. Ann N Y Acad Sci 1989; 557: 87-99.

23 Weiss G, Wachter H, Fuchs D. Linkage of cell-mediated immunity to iron metabolism. Immunol Today 1995; 16: 495-500.

24 Fuchs D, Hausen A, Reibnegger G, Werner ER, WernerFelmayer $G$, Dierich MP et al. Immune activation and the anaemia associated with chronic inflammatory disorders. Eur J Haematol 1991; 46: 65-70.

25 Rogers IT, Bridges KB, D urmowicz G P, Glass J A uron PE, Munro $H N$. Translational control during the acute phase response. Ferritin synthesis in response to interleukin-1. Biol Chem 1990; 265: 14 572-8.

26 Rogers JT. Ferritin translation by interleukin-1 and interleukin-6: the role of sequences upstream of the start codons of the heavy and light subunit genes. Blood 1986; 87: 2525- 37.

27 Heinrich PC, Castell JV, Andus T. Interleukin-6 and the acute phase response. Biochem J 1990; 265: 621-36.

28 Atkins M B, Kappler K, M ier JW, I saacs RE, Berkman EM. Interleukin-6 associated anemia: determination of the underlying mechanism. Blood 1995; 86: 1288-91.

29 Nieken J, Mulder NH, Buter J, V ellenga E, Limburg PC, Piers DA et al. Recombinant human interleukin- 6 induces a rapid and reversible anemia in cancer patients. Blood 1995; 86: $900-5$ 